Resumen: La presente edición de noticias propone reflexionar acerca de cómo la moda, con su capacidad para expresar el espíritu de la época, contribuye a visibilizar uno de los problemas contemporáneos más acuciantes de la humanidad: el movimiento global de personas que se ven obligadas a abandonar sus hogares debido a conflictos locales, persecución o pobreza. A través de ejemplos locales e internacionales, se analiza el trabajo de una generación de diseñadores emergentes que no duda en manifestar su visión o embarcarse en la búsqueda de soluciones concretas. A su vez, indaga en la naturaleza mixta de la moda y la relación entre la industria, los migrantes y el trabajo.

Palabras clave: moda - migrantes - diversidad - identidad - diseño social - política de la moda.

[Resúmenes en inglés y portugués en las páginas 92-93]

(1) Luego de una carrera en el área de comunicación y marketing especializada en medios, viajó a Costa Rica con el deseo de retomar, al menos por un tiempo, el contacto con la naturaleza que experimentó de chica. A los tres años regresó a Buenos Aires y creó el blog La moda en serio, un espacio donde reflexionar sobre la moda y el diseño como agentes de cambio. La moda también resultó el punto de encuentro para otros de sus intereses y estudios, como las ciencias naturales y el arte. Colabora en L'Officiel Argentina, la revista digital Áurea y La Nación Moda \& belleza.

\title{
Una mirada desde la moda
}

La moda es una forma de comunicación y de participación. No se trata solo de las imágenes perfectas que alimentan nuestra cultura visual cotidianamente; la moda es sobre la gente real, nuestra identidad, modos de pensar y de sentir. En la actualidad, no permanece indiferente frente al movimiento global de personas que se ven obligadas a abandonar sus hogares por conflictos locales, persecución o pobreza. Siendo la moda arte y parte en uno de los problemas contemporáneos más acuciantes, contribuye a hacerlo visible. 
La edición número 58 de La Bienal de Venecia que tuvo lugar de mayo a noviembre del año 2019, fue el escenario de Dress For Our Time, una performance destinada a crear conciencia sobre el drama de los refugiados. Helen Storey, artista, diseñadora y docente en el London College of Fashion, creó el Vestido para nuestro tiempo a partir de una carpa en desuso que albergó a una familia en un campamento en Jordania. El material fue donado por el Alto Comisionado de las Naciones Unidas para los Refugiados - ACNUR.

En el año 2016, el vestido fue parte de la exhibición Nuestras Vidas en Datos en el Museo de Ciencia de Londres. En esa oportunidad, se proyectó sobre la prenda una animación formada por puntos de luz. Cada uno de ellos representaba cien vidas humanas. Las luces fluyeron desde seis puntos, representando el $50 \%$ de la población global de refugiados que involucra a Europa, el Norte de África y Medio Oriente. El resultado fue un mapa en movimiento de la migración humana. En esa oportunidad, la profesora declaró:

En todo el mundo, una de cada 113 personas en el planeta es un refugiado, un desplazado interno o alguien que está buscando resguardo, pero los números no significan nada si no afectan nuestro corazón. Este proyecto utiliza el poder de la moda para ayudarnos a conectar con lo que solía ser inimaginable y se pregunta cómo todos y cada uno de nosotros podemos seguir siendo humanitarios en un momento de cambio colosal e irreversible (Storey, 2016).

Acciones artísticas y conceptuales como ésta, conviven con propuestas que desde el diseño, buscan soluciones específicas. Si bien estas últimas no son sujeto del presente escrito, vale mencionar algunos ejemplos. En enero de ese mismo año, un grupo de estudiantes del Royal College of Art de Londres presentó un prototipo de abrigo que se transforma en una carpa y en una en bolsa de dormir, declaró a Dezeen Harriet Harris, una de las líderes del proyecto:

El buen diseño no se trata de dispositivos, tiene un corazón social y un papel que desempeñar. En este momento las soluciones son limitadas y el sufrimiento no parece detenerse. Si bien nuestro dispositivo no soluciona todo el problema, aborda una pequeña parte de él (Dezeen, 2016, s/p).

En octubre del año 2016, la misma publicación daba cuenta del proyecto de los diseñadores holandeses Didi Aaslund y Floor Nagler. Con los botes de goma y chalecos salvavidas que quedaban abandonados en las costas de la isla de Lesbos, Grecia, idearon la mochila $B A G 2 W O R K$ para emplear a los refugiados. "Si queremos que los recién llegados se integren, tenemos que ayudarlos a que vuelvan a trabajar”, expresó el dúo” (Dezeen, 2016, s/p).

\section{La escena multicultural}

La naturaleza de la moda es mixta, y en los últimos años viene respondiendo a las demandas de una sociedad más inclusiva. Sin embargo, desde el mainstream, esta apertura hacia la diversidad muchas veces parece tener un tono cosmético, más que responder a 
un cambio de paradigma real. A menos que los cambios se hagan desde adentro, como parece venir a demostrar Edward Enninful, el nuevo editor en jefe de la edición británica de Vogue. Vale mencionar que aunque este y otros ejemplos provengan de lugares lejanos, la moda global aún responde a la hegemonía de las capitales de la moda, por lo que su influencia nos alcanza, tarde o temprano.

Bajo la dirección de Enninful, Rihanna fue la primera mujer negra en protagonizar la portada del número de septiembre en 2018 luego de 12 años. Entrevistado por Robin Givhan para The Washington Post, el editor se describe a sí mismo como europeo, africano y británico, en ese orden. Nació en Ghana, pero se crió en un barrio londinense poblado por los recién llegados de África y el Caribe, así como los de ascendencia china, gays y blancos de clase trabajadora.

En casa vivía en África: la comida, la ropa, las personas que venían a visitar a mis padres. Y cuando iba a la escuela, estaba en Inglaterra. Crecí en esa diversidad, aunque ni siquiera sabía cómo se llamaba. Siempre ha sido parte de mí, de mi familia y mi educación” declaró Enninful y agregó: “Todas estas revistas están poniendo a estas increíbles mujeres de color en la tapa, y espero que no sea solo una moda. La única forma real de evitar que sea una moda, es hacer que gente más diversa trabaje detrás de escena (The Washington Post, 2018, s/p).

El editor menciona la palabra clave: trabajo. Las consecuencias de la economía global basada en el crecimiento, son cada vez más críticas para los seres humanos y el medio ambiente, y la industria de la moda ha contribuido con la precarización laboral de regiones que tarde o temprano, expulsarán a sus habitantes. La pérdida de talento que lamenta el sistema frente al endurecimiento de las fronteras, tiene un trasfondo económico. Detrás de la celebración de la escena multicultural, un subtexto parece decir: valoramos sus saberes, habilidades y riqueza cultural, pero mejor quédense en su casa. La falta de trabajo nos enfrenta a unos y a otros, y favorece la aparición de nacionalismos.

En ese sentido, Gales del Sur es una de las regiones que ha sido el blanco de las críticas por apoyar la salida del Reino Unido de la Unión Europea. A su vez, ha sido víctima del desempleo durante décadas. La estilista Charlotte James y la fotógrafa Clémentine Schneidermann se valieron de la moda para explorar las complejidades de la desindustrialización y lo que eso significa para las personas, las familias y las comunidades. Las dos mujeres vienen dictando talleres de estilismo y costura para los más jóvenes desde el año 2015. El resultado quedó registrado en la muestra fotográfica itinerante llamada It's Called Ffasiwn, que en marzo del 2019 se presentó en la Martin Parr Foundation.

\section{Pasarelas políticas}

En los shows de moda, las referencias a la crisis de los refugiados aparecen de manera más o menos literal. El diseñador de origen turco-chipriota Hussein Chalayan, por ejemplo, se refirió a la tensión parisina y a los efectos de una inmigración no integrada, a través 
del nombre de la colección otoño invierno 2018. La llamó Périphérique, en relación a la carretera que rodea París y separa la ciudad de los suburbios, donde los inmigrantes viven apartados (Pre-Fall, 2018; Chalayan, Vogue, 2018).

Por su parte, el belga Raf Simons abrió y cerró su primera colección para Calvin Klein en el año 2017 con la canción Esto no es América de David Bowie, en rechazo al muro propuesto por Trump. Para la prensa especializada, solo un inmigrante pudo representar con tanta fuerza la tensión del momento.

En febrero de ese mismo año, el diseñador Gareth Pugh respondió al clima político circundante en la presentación otoño invierno 2017 en la semana de la moda de Londres. Lo describió como "ambiguo y preocupante, donde el instinto predominante es construir muros, reforzar fronteras y reclamar territorio". La colección se inspiró en el polémico thriller de 1974, Portero de Noche, una historia ambientada en un campo de concentración nazi. Agregó: "Que tal sobrecarga sensorial pueda conducir a una procesión majestuosa de siluetas arquitectónicas y prendas de vestir, casi exclusivamente en telas recortadas y poco exigentes, habla de una disciplina de pensamiento" (Dezeen, 2017, s/p).

Unos meses más tarde, en julio del año 2017, Viktor \& Rolf presentó su colección Action Dolls en la semana de la alta costura de París. "El patchwork sirve para simbolizar un deseo de armonía, para crear unidad a través de la diversidad", dijeron los diseñadores a Vogue.

Dimos nueva vida a tejidos antiguos procedentes de mercados vintage y de nuestro archivo personal, buscamos esencialmente transformar algo viejo y desechado en algo surrealista y artesanal. Estas muñecas están luchando por un mundo mejor a través de ese mosaico que simboliza unidad, concluyeron (Vogue, 2017, s/p).

En su colección otoño invierno 2019, el diseñador londinense de 27 años Samuel Ross -creador de la marca A Cold Wall- exhibió una variedad de chalecos de protección y prendas de punto superpuestas destinadas a la "autoconservación y la supervivencia"(Dezeen, $2019, \mathrm{~s} / \mathrm{p}$ ). La pasarela transcurrió entre dos canales de agua, destinados a representar la travesía de los refugiados. La ropa incluyó detalles alusivos al tema como colores reflectantes, detalles de goma y brújulas integradas. "La colección habla del color y la temperatura de la era que transitamos. Es el despertar de la agitación política y la crisis mundial de los migrantes", dijo la marca (Dezeen, 2019, s/p).

Para la colección masculina primavera verano 2020, el diseñador Rick Owens honró sus raíces mexicanas en reacción al muro propuesto por el presidente Trump. Eligió nombrarla como el apellido de su abuela: Tecuatl y explicó en las notas de prensa de la presentación:

Mi madre (mexicana nativa) y yo aprendimos inglés juntos cuando comenzó a llevarme a la guardería, y mi padre trabajó en la corte de Porterville como traductor para los trabajadores agrícolas migrantes mexicanos, que eran una parte importante de la industria agrícola de San Joaquín (Dazed Digital, 2019, s/p).

Pero Owens no se conformó con hacer una declaración política en la pasarela. Lo ganado por la venta de las remeras y camisas para las que empleó el logo del águila azteca de la 
Asociación de Trabajadores Agrícolas, irá para la causa. Como muestra de su compromiso, el diseñador continuó con el tema en la siguiente colección presentada en París meses más tarde (Owens SS20 Menswear, Dazed Digital, 2019, s/p).

\section{Entre dos mundos}

Para el periodista especializado Felix Petty, las mejores colecciones de la temporada otoño invierno 2019 en la semana de la moda londinense, tomaron posición frente al Brexit, indagando en la identidad cultural británica. "Lucharon apasionadamente por una visión de Gran Bretaña como un espacio para la diversidad y la hibridación, la protesta y la creatividad" (i-D, 2019, s/p). Petty señala que existe una generación de diseñadores emergentes que está lidiando con la identidad moderna: los hijos de inmigrantes, la segunda generación, los atrapados entre dos mundos, los desplazados de su lugar natal (i-D, 2019, s/p). En la Argentina, la influencia de los movimientos migratorios tan íntimamente relacionados con su historia, así como los desplazamientos internos, permanece hasta hoy.

La transformación morfológica de las mangas y los delantales, dos de las características más identitarias de la diseñadora Vicki Otero, encuentran sus raíces en un relato de mujeres migrantes y el trabajo.

Creo que hoy los diseñadores tenemos el compromiso de contarnos desde nuestro lugar. Soy hija de una española que llegó como inmigrante de un lugar muy pobre. Mis abuelas eran de una aldea, trabajaban en el campo. Tengo fijadas en la cabeza las pocas fotos que existen de ellas, trabajando la tierra y cuidando los animales. Estaban todas vestidas de negro y de largo, con unos delantales impecables. Llevaban las mangas arremangadas para trabajar (La moda en serio, 2017, s/p).

Para la presentación en Bafweek de la colección Verano 2017 llamada Industria Argentina, la diseñadora recreó el ambiente de un taller textil ambientado en los años 1940 / 1950. El amor por el oficio y el respeto por las personas que lo ejercen, se hizo presente en las herramientas y el espacio de trabajo. El timbre fabril que marcaba los finales de turno incluido en la banda de sonido, transportó a los asistentes a una época en la que el trabajo era la base del progreso.

La diseñadora Juliana García Bello se mueve con naturalidad entre el arte y la indumentaria. Su proyecto Cascote Abandonado (que incluye piezas de joyería contemporánea y esculturas), indaga en el origen de la población de su lugar natal, Tierra del Fuego:

Alguien me dijo que en la historia de los fueguinos hay algo de abandono, producto de los exilios que son parte de la génesis de su población. Siempre se deja algo atrás cuando se va hacia otro lugar. Me interesa reconstruir y relatar la historia colectiva (La Nación Moda y Belleza, 2018, página 8). 
La ganadora de Autores de Moda BA presentó su colección Dora Duba en la última edición de Bafweek y en Río Grande. Allí, fue al aire libre con una casa trineo, la vivienda típica que puede trasladarse de un lugar a otro y caracteriza la naturaleza nómade de sus habitantes. Por su parte, el diseñador Matías Hidalgo se refirió a su modo de ver la moda luego de presentar su colección primavera verano 2019 en Frankfurt, y resultar elegido como uno de los diseñadores emergentes más destacados del mundo por la edición italiana de Vogue en el 2018.

Siempre me interesó indagar en los orígenes y lo intercultural, ese fue el tema de mi tesis. Me fascina ver cómo la hibridación cultural se refleja en los textiles. Eso ancla mi inspiración, es algo real en mí. Me gusta provocar y desconcertar, mezclar lo étnico, que no se entienda, jugar con mi identidad. Lo hago incluso desde mi forma de vestir (La Nación Moda \& Belleza, 2018, p. 5).

Sus indagaciones trascienden cuestiones estéticas para adentrarse en los modos de hacer. "Me interesa la forma de confección de los árabes, que es muy diferente a la occidental. Las prendas están pensadas desde el textil, respetan la pieza de tela", señaló el diseñador (La Nación Moda \& Belleza, 2018, p. 5).

La diseñadora argentina Lucía Chain, elegida para participar de la exhibición Sustainable Thinking en el Museo Ferragamo de Florencia, declaró que le resultó natural vincular parte de su historia personal con la situación que atraviesa la humanidad en relación a las migraciones.

Presenté el conjunto rector de mi colección de invierno, llamada 23, inspirada en unos papeles de mi abuela. Entre ellos, encontré una declaración formal de aduana que detalla el contenido de la valija con la que ella ingresó a Argentina desde Hungría a comienzos del siglo pasado. 23 es el número total de piezas registradas. La pregunta que me surgió fue ¿Qué cosas llevarías con vos en caso de tener que elegir un número tan acotado, para llegar a un destino del que no conoces absolutamente nada? (La Nación Moda \& Belleza, 2019, s/p).

Para la diseñadora Carla Andrea Escalera, la historia de su familia de origen es ineludible a la hora de describir cuales son sus motivaciones más profundas. La colección primavera verano 2020 con la que ganó el concurso Autores de Moda BA en julio del 2019, se inspiró en la tierra de su madre.

Mi mamá se interesó mucho por la flora fueguina, de hecho, investigó y escribió un libro sobre el tema. Ella nació en Misiones y se fue de muy joven a Tierra del Fuego por trabajo. Sueña con volver, dice que le vuelve el alma al cuerpo cuando pisa tierra misionera. Yo retomé ese afán por conocer más, pero lo apliqué a investigar los tintes naturales de mi lugar. PY'AGUASU es una palabra de origen guaraní que significa valor. También es el nombre de una canción y un poema muy bonito. Me gusta sonoramente. La colección retoma la conexión con la tierra de mi mamá, donde la naturaleza es selva, exuberancia y tierra 
colorada. Eso también es parte de mí, de chica viví un tiempo allá. Todos los veranos viajábamos por tierra desde Río Grande a Misiones (La Nación Moda \& Belleza, 2019, s/p).

\section{Otros ámbitos para la moda}

La universidad es el lugar en el que se debaten y establecen nuevos paradigmas para la sociedad en su conjunto. En el proyecto LentoModeOn, liderado por el profesor Gustavo Lento, el estudio del diseño de indumentaria tiene un marco ideológico ineludible.

Para la primera edición del año 2017 elegimos a los muros como paradigma. Personalmente, pensé que después de la caída del Muro de Berlín no había lugar en el mundo para más. Lamentablemente se vuelve a hablar de ellos. Con esta presentación apelamos a correr las fronteras y a derribar muros: los míos, los tuyos, los de Trump ¿De qué sirve la creatividad si no está anclada en la humanidad? (La moda en serio, 2017, s/p).

Los museos es otro de los ámbitos en los que se debaten las ideas que atraviesan nuestro tiempo y dan forma al paisaje cultural. Con este objetivo, y bajo diversos enfoques, las migraciones y sus consecuencias son sujeto de análisis y reflexión.

La exhibición Home Is a Foreign Place en The Met Breuer inaugurada en abril del año 2019, explora el significado de las palabras hogar y lugar a través de las obras de arte contemporáneo recientemente adquiridas de América Latina, Medio Oriente, África del Norte y el sur y sudeste de Asia, junto con obras de icónicos artistas estadounidenses de la colección The Met. El texto curatorial de la muestra señala:

El arte contemporáneo y los movimientos vanguardistas anteriores del arte moderno no tienen un origen único, ni se desarrollan de forma aislada. Desde la década de 1940, los artistas han buscado nuevas formas de expresión a medida que han vivido eventos culturalmente transformadores, desde guerras devastadoras, injusticias sociales y humanitarias y migraciones masivas, hasta cambios económicos y ambientales. Estas historias continúan impactando y dando forma al arte de nuestro tiempo (The Met Breuer, abril 2019).

En la moda, al igual que en otras disciplinas como el arte textil, también se verifican reflexiones en torno al hogar en relación a las migraciones, deseadas o no. En ese sentido, la diseñadora Celine Semaan Vernon, quien de niña huyó del Líbano, creó un collar de oro blanco denominado Estamos en casa. La pieza es una llave hecha en Beirut, similar a la de la casa de su propia familia y refiere a la tradición de los refugiados de colgar de su cuello la llave de su hogar, con la esperanza de retornar algún día. Parte de las ganancias se destinaron a un fondo destinado a brindar capacitación laboral para los refugiados (Slow Factory, 2017). 
En el ensayo La Tela como Memoria, la investigadora y profesora Pennina Barnett, cofundadora de Textile: The Journal of Cloth and Culture, analiza la obra de Do Ho Suh para rastrear vínculos entre los textiles y el sentido de pertenencia. El artista nacido en Corea del Sur, crea enormes instalaciones en las que reproduce su hogar y el de otros a escala natural, valiéndose de varillas y telas traslúcidas cosidas a mano. A pesar de haber vivido en Nueva York por muchos años, siempre ha sido consciente de la incomodidad y la no-familiaridad de su casa, producto de pertenecer a una cultura diferente.

Suh siente la necesidad de recrear físicamente espacios retenidos en la memoria para llevarlos consigo a donde vaya. A pesar de que declara no extrañar su hogar, un sentido de anhelo impregna su trabajo. Fue a través de una pieza temprana (1999) que encontró un modo de lidiar con la añoranza y el desplazamiento cultural. Seoul Home fue modelado en base a la casa de su infancia, es en sí una réplica de la casa de un erudita del Siglo XIX. Suh midió cada pulgada de la casa de sus padres, encontrando aquí y allá las marcas que había hecho cuando niño. "Cuando pasas por ese proceso, el espacio se vuelve parte de ti; realmente sientes que lo conoces. Está en ti, y entonces te puedes ir sin ninguna atadura", dijo Do Ho Su (Barnett, 2017, p. 2).

El Museo de Moda de Amberes, anunció la exhibición Cutting Fabrics, Breaking Borders: Textile as Resistance para el año 2020. La muestra, creada en colaboración con la periodista Samira Bendadi y el fotógrafo Mashid Mohadjerin, propone tomar a la ropa y a los textiles, como disparadores de historias que trascienden las fronteras religiosas, culturales y nacionales.

Refugio, resistencia, esperanza, felicidad, tradición, belleza, espiritualidad y descolonización. Los textiles son, y han sido durante mucho tiempo, un poderoso medio para expresar la identidad, especialmente en tiempos de guerra y crisis. ¿Qué mensajes e historias pueden compartir las telas? ¿Qué dice un atuendo o una prenda sobre el usuario? ¿Pueden los textiles tejer el pasado junto con el presente? ¿Pueden ser un acto de resistencia? Preguntas importantes que vale la pena explorar para hacernos una imagen más completa de nuestras sociedades modernas y personas inspiradoras de todo el mundo (MoMu, 2019).

Volviendo al vínculo entre la tela y la memoria, la investigadora textil Pennina Barnet expresa en su ensayo Cloth and / as Memory

Si la fotografía captura el instante, la tela y la ropa contienen el tiempo de manera diferente; retienen una huella en tiempo continuo. Como Peter Stallybrass lo describe: la tela 'nos recibe'. Cobra vida, es animada y transformada por nuestros movimientos. Se desgasta en los codos y el doblez de las rodillas, se rompe cuando caemos. Hasta podríamos decir que la tela es un tipo de memoria, encarnada y material (2017, p. 1). 
Cuando el hogar se convierte en un lugar extraño, las prendas son el vestigio que llevamos puesto. La moda, además de comunicar, puede contribuir a reparar el tejido social a partir de la generación de trabajo digno e inclusivo. El trabajo es, quizás, el refugio más deseado por quienes buscan una vida mejor y muchas veces, una vida posible.

\section{Lista de Referencias}

A Cold Wall reflects on global migrant crisis in Autumn Winter 2019 collection. Dezeen (9 de enero 2019). Recuperado el 15/04/2019 de https://www.dezeen.com/2019/01/09/ cold-wall-autumn-winter-2019-birth-organ-synth-london-fashion-week-mens-2019

Doll Heads Aside, Viktor \& Rolf Are as Committed to Eco-Conscious Couture as Ever. Vogue (7 de julio 2017). Recuperado el 15/04/2019 de https://www.vogue.com/article/ viktor-rolf-fall-2017-couture-behind-the-scenes-patchwork-upcycling-dolls

Educación de moda: Proyecto \#LentoModeOn" (9 de julio 2017) La moda en serio. Recuperado el 17/05/2019 de https://lamodaenserio.com/educacion-de-moda-proyectolentomodeon/

Exhibition Our Lives In Data (15 de julio 2016). Science Museum, Londres. Recuperado el 20/04/2019 de https://www.sciencemuseum.org.uk/about-us/press-office/dress-ourtime-science-museum-unites-data-and-fashion-explore-global

Exhibition Overview: Home Is a Foreign Place (9 de abril 2019). The Met Breuer. Recuperado el 30/03/2019 https://www.metmuseum.org/exhibitions/listings/2019/home-is-aforeign-place

Fashion, Brexit and British Identity (5 de marzo 2019) $i-D$. Recuperado el 15/05/2019 de https://i-d.vice.com/en_uk/article/a3baz8/fashion-brexit-and-british-identity

Gareth Pugh responds to political climate with Autumn Winter 2017 collection (21 de febrero 2017) Dezeen. Recuperado el 15 de mayo de https://www.dezeen.com/2017/02/21/ gareth-pugh-design-current-political-climate-autumn-winter-2017-collection-londonfashion-week/

Is Edward Enninful the next Anna Wintour? (19 de noviembre 2918). The Washington Post. Recuperado el 15 de mayo de https://www.washingtonpost.com/graphics/2018/lifestyle/ edward-enninful-vogue-fashion-editor/

It's Called FFASIWN by Scheneidermann, C. and James. C. (27 de marzo 2019). Martin Parr Foundation. Recuperado el 15/6/2019 de https://www.martinparrfoundation.org/ exhibitions/its-called-ffasiwn/

La diseñadora fueguina que diseña a partir de cascotes (15 de diciembre 2018). La Nación Moda \& Belleza.

La tela como memoria, Barnett, P. (22 de noviembre 2017) La moda en serio. Recuperado el 15/06/2019 de https:/lamodaenserio.com/la-tela-memoria-pennina-barnett/

Pre-Fall 2018 Chalayan (23 de enero 2018) Vogue. Recuperado el 16/05/2019 de https:// www.vogue.com/fashion-shows/pre-fall-2018/chalayan

Quién es uno de los diseñadores argentinos destacados en el mundo (24 de noviembre 2018). La Nación Moda \& Belleza. 
Quiénes son los diseñadores argentinos que se presentan en pasarelas internacionales (25 de enero 2019) La Nación Moda \& Belleza. Recuperado el 2/06/2019 de https:/www. lanacion.com.ar/moda-y-belleza/quienes-son-disenadores-argentinos-se-presentanpasarelas-nid 2213978

RCA students design wearable dwelling for Syrian refugees (27 de enero 2016). Dezeen. Recuperado el 15/05/2019 de https://www.dezeen.com/2016/01/27/royal-college-of-artstudents-wearable-coat-tent-dwelling-syrian-refugees/

Refugee-made backpacks are produced from recycled life vests and boats (28 de octubre 2918). Dezeen. Recuperado el 6/06/2019 de https://www.dezeen.com/2016/10/28/ bag2work-backpacks-recycled-refugee-boats-life-vests-fashion-kickstarter-dutchdesign-week-2016/

Rick Owens responds to Trump's wall by exploring his Mexicanness for SS20 (20 de junio 2019). Dazed. Recuperado el 15/08/2019 de https://www.dazeddigital.com/fashion/ article/44948/1/rick-owens-trump-wall-mexico-paris-fashion-week-tecuatl-ss20-parisfashion-week

Suprarreciclaje. Los desechos industriales de Tierra del Fuego se convierten en ropa de diseño (14 de agosto 2019). La Nación Moda \& Belleza. Recuperado el 5/09/2019 de https://www.lanacion.com.ar/moda-y-belleza/suprarreciclaje-los-desechos-industrialestierra-del-fuego-nid2277203

Textile as Resistance (agosto 2019) MoMU Antwerp. Recuperado el 4/08/2019 de https:// www.momu.be/en/exhibitions/samira-bendadi-mashid-mohadjerin-textiel-in-verzet

The Dress For Our Time travels to Italy for the Venice Biennale 2019 (16 de mayo 2019). London College of Fashion. Recuperado el 15/06/2019 de https://www.arts.ac.uk/colleges/ london-college-of-fashion/stories/dress-for-our-time-venice-biennale

Vicki Otero, cuando el diseño cuenta la propia historia (15 de agosto 2017) La moda en serio. Recuperado el 4/04/2019 de https://lamodaenserio.com/vicki-otero-diseno-e-identidad/

We are Home (2017) Slow Factory. Recuperado el 22/06/2019 de https://slowfactory.global/ pages/we-are-home

\begin{abstract}
This text proposes to reflect on how fashion, with its capacity to express the spirit of the time, contributes to visualize one of the most pressing contemporary problems of humanity: the global movement of people who are forced to abandon their homes due to local conflicts, persecution or poverty. Through local and international examples, will analyse the work of a generation of emerging designers who do not hesitate to express their vision or seek concrete solutions. In turn, the text will investigate the mixed nature of fashion and the relationship between industry, migrants and work.
\end{abstract}

Keywords: fashion - migrants - diversity - identity - social design - fashion politics.

Resumo: O presenta texto propõe refletir de que forma a moda, com sua capacidade para expressar o espírito de uma época, contribui para a visibilização de um dos problemas 
contemporâneos mais preocupantes da humanidade: o movimento global de pessoas que são obrigadas a abandonar seus lares devido a conflitos locais, perseguição e pobreza. Utilizando exemplos locais e internacionais, analisará o trabalho de uma geração emergente de desenhadores que não duvidam em manifestar sua visão ou aventurar-se na busca de soluções concretas. Por sua vez, adentrará na natureza mista da moda e a relação entre a indústria, os migrantes e o trabalho.

Palavras chave: moda - migrantes - diversidade - identidade - desenho social - política da moda.

[Las traducciones de los abstracts fueron supervisadas por el autor de cada artículo] 